\title{
DE VIAJE... CAPTANDO DESPLAZAMIENTOS CORPÓREOS EN UNA CIUDAD QUE EDUCA ${ }^{1}$
}

On trip: capturing bodily displacements in a city that educates

\section{William Moreno Gómez}

Profesor de pregrado y posgrado de la Universidad de Antioquia (Colombia), coordinador grupo de investigación PEs (Prácticas Corporales, Sociedad, Educación-Currículo)

\section{María Isabel Herrera Velásquez, Daniel Hincapié Bedoya y Santiago Marulanda Hoyos \\ Estudiantes Instituto de Educación Física de la Universidad} de Antioquia, integrante semillero PES

\section{RESUMEN:}

El texto presenta ribetes del drama que viven los niños, niñas y adolescentes (en adelante NNA) de Medellín (Col). Presenta la génesis y el sentido del viaje. Lo hace a través de una metodología de corte derivana ${ }^{2}$ que viene practicando el grupo de investigación Prácticas Corporales, Sociedad, Educación-Currículo (en adelante PES) en sus pesquisas, especialmente en los procesos de formación investigativa que adelanta su semillero desde hace ya siete años. Experiencia investigativo formativa que se interesa por la resignificación de las prácticas ludocorporales (en adelante LC) institucionalizadas y no institucionalizadas y su sentido en la configuración y reconfiguración del entramado social de la ciudad. Finalmente, documenta situaciones sociales, prácticas de ciudad captadas por la lente del viajante; obturaciones en medio de las cuales se dejan leer desplazamientos corpóreos que muestran acciones de talante

1. Este trabajo está asociado a la propuesta «El viaje...» del semillero del grupo de investigación Prácticas Corporales, Sociedad, Educación —Currículo- (PES) de la Universidad de Antioquia.

2. Metodología inspirada en los aportes de la Teoría de la Deriva desarrollada por Guy Debord en la que se investiga a partir de la experiencia viajera por la ciudad. 
lúdico, recreativo y existencial de los dependientes de la ciudad. Escapes que dejan ver la voluntad de algunos habitantes emblemáticos escribiendo ciudad; experiencias LC que suman en la cinética y el pulso de la energética urbana de una ciudad fragmentada, movilizada por cosmovisiones e intereses diversos. La ciudad tiene sonido, olor, sabor y textura; salta, ama y copula, juega, sueña, trabaja, se alimenta, baila: tiene motricidad.

Palabras Clave: prácticas corporales, educación, ciudad, viaje.

RESUM: El text presenta rivets del drama que viuen els xiquets, les xiquetes i adolescents (d'ara endavant XXA) de Medellín (Colòmbia). Presenta la gènesi i el sentit del viatge. Ho fa a través d'una metodologia de caràcter «derivà», ${ }^{3}$ la qual practica el grup de recerca Prácticas Corporales, Sociedad, Educación-Currículo (d'ara endavant PES) en les seues indagacions, especialment en els processos de formació investigadora que avança el seu planter des de fa ja set anys. Experiència investigadora i formativa que s'interessa per la ressignificació de les pràctiques ludocorporals (d'ara endavant LC) institucionalitzades i no institucionalitzades i el seu sentit en la configuració i la reconfiguració de l'enxarxat social de la ciutat. Finalment, documenta situacions socials, pràctiques de ciutat captades per la lent del viatjant; obturacions enmig de les quals es deixen llegir desplaçaments corporis que mostren accions lúdiques, recreatives i existencials dels dependents de la ciutat. Fugides que deixen veure la voluntat d'alguns habitants emblemàtics que escriuen la ciutat; experiències LC que sumen en la cinètica i el batec de l'energètica urbana d'una ciutat fragmentada, mobilitzada per cosmovisions i interessos diversos. La ciutat té so, olor, sabor i textura; salta, estima i copula, juga, somia, treballa, s'alimenta, balla: té motricitat.

PARAULES CLAU: pràctiques corporals, educació, ciutat, viatge.

ABSTRACT: The paper portrays traces of the drama experienced by children and adolescents from Medellin (Columbia). It presents the genesis and direc-

3. Metodologia inspirada en les aportacions de la Teoria de la Deriva, desenvolupada per Guy Debord en la qual s'investiga a partir de l'experiència viatgera per la ciutat. 
tion of a journey through a methodology of drifting ${ }^{4}$ applied by the research group «Bodily Practices, Society, Education-Curriculum» in their investigations, especially in the processes of research training advanced over the last seven years. This formative research experience explores the resignification of institutionalized and non-institutionalized ludic-corporal practices and their meaning in the configuration and reconfiguration of the social fabric of the city. Finally, the article documents social situations, practices from the city captured by the traveler's lens; snapshots in the midst of which bodily displacements reveal the leisure, recreational and existential actions of the city's dependents. Expressions of the will of emblematic individuals writing the city; ludic-corporal experiences added to the kinetics and the pulse of urban energy of a fragmented city, mobilized by diverse world views and interests. The city has sound, smell, taste and texture; it jumps, loves and copulates, plays, dreams, works, eats, dances: it has movement.

KEYWORDS: corporal practices, education, city, travel.

\section{Contexto: el drama de los niños y las niñas en la ciudad que viajamos}

$\mathrm{J}^{\mathrm{cot}}$ enny Pearce (2014), directora del Centro Internacional de Estudios de Participación del Departamento de Estudios de Paz de la Universidad de Bradford (Reino Unido), recordaba en el seminario de Barcelona que Steven Pinker en uno de sus últimos trabajos, analizando la reducción de la violencia en la historia, encontró interesantes cuestiones que se deberían tener en cuenta en Colombia: que el Estado ha sido uno de los actores que más ha disminuido la violencia en el mundo. Una pasada detenida por Latinoamérica le hubiera confundido: «Amo más terrible que los viejos tiranos y déspotas... amo sin rostro, desalmado y que no obra como un demonio sino como una maqui-

4. Methodology inspired by the contributions of the Theory of the Dérive developed by Guy Debord in which the starting point is the traveling experience in the city. 
na». ${ }^{5}$ El hallazgo de Pinker nos lleva a pensar que en Colombia, justamente, el Estado, cual «ogro filantrópico» de la violencia, es perverso, reproduce la violencia, ya no cuasi legalizada, «sin legitimación»; históricamente, «la violencia por la violencia» en función de intereses mezquinos.

Siendo la historia de Colombia, la de un capitalismo feroz, sanguinario y avasallante, la reducción visible de la violencia, sugiere, puede provenir de diversas motivaciones, de pactos entre actores; donde el Estado es un igualado a conveniencia de las elites en gobierno real. Plantea Pearce (2014) que la violencia es somática, sostiene que todos los tipos de violencia, directa, estructural o simbólica realmente son impactos sobre el cuerpo de las personas. De ese cuerpo, bajo esa condición, y en pretensión de ciudad que educa, queremos hablar. Hay gente que en su experiencia y en su experiencia ciudad le hacen un quite dinámico a la guerra y desde allí dibujan ya trazos de una ciudad y una educación otra. Nos interesamos por ello y por ellos; gente de la educación y el juego. Viajeros inquietos de los que no queremos perder contexto de lo que pasa con el cuerpo en su experiencia más divertida, creativa y placentera pero a la vez en contextos de un drama extremo.

En medio de los intentos de pacificación, se presenta un incremento significativo en las acciones de reclutamiento de jóvenes entre 12 y 17 años, se evidencia la utilización ilícita de NNA por parte de combos y grupos armados desmovilizados para el expendio de drogas y el trasporte de armas. Cerca de 18.500 nNA de las comunas $(8,10,13$ y 16) y de los corregimientos (San Antonio de Prado y Altavista) de la ciudad de Medellín se encuentran en situación de riesgo de reclutamiento y utilización ilícita por parte de estos grupos. Las niñas, adolescentes y mujeres están expuestas a actos de explotación sexual con fines comerciales, al acceso carnal violento, la prostitución forzada y la esclavitud sexual. El cuadro es crítico; en el último año, el Instituto de Medicina Legal registró en la ciudad un total de 1.258 homicidios, de ellos 117 eran menores de edad ${ }^{6}$.

5. In memoriam Octavio Paz. El ogro filantrópico publicado en Vuelta número 21, agosto de 1978 y presentado en Cuadernos de Economía número 28. http://www.bdigital. unal.edu.co/24319/1/21465-73312-1-PB.pdf.

6. Fuente: informes de la Defensoría del Pueblo sobre estado de los DDHH (2013 y 2014). 
Según Carlos Velandia, reinsertado del Ejército de Liberación Nacional (ELN), los costos de la guerra son inconmensurables, admite que el efecto sobre niños y adolescentes implica una hipoteca de muchas generaciones, insiste en que el país acaba con su capital más preciado (Corporación Mandala 2015). La huella de la guerra es visible en los NNA sacrificados, pero también en los cuerpos de los que quedan; estamos hablando de los reclutados, los sometidos a manipulación y los torturados, todos ellos testigos de excepción de los peores cuadros de la guerra. El potencial interactivo queda lacrado en las márgenes de la «incivilidad y la indecencia», este costo generalmente es ignorado por la estadística del conflicto y allí el papel «positivo y negativo» de la educación es invaluable. ${ }^{7}$ Según Pía Britto (2016) desde Desarrollo Infantil Temprano de UNICEF: «El conflicto priva a los niños de la seguridad, la familia, los amigos y el juego, elementos que potencian el desarrollo y aprendizaje». Coincidimos en que el acceso a una buena educación, a una ciudad amable — donde el juego es posible - es vital para la estimulación social de las nuevas generaciones.

En la reducción de las desigualdades sociales y la conciliación de los mundos rural y moderno, en el desarrollo de una educación otra, en el desarrollo de una educación pertinente con los retos curriculares que plantea el contexto temporal de la guerra, podría descansar parte del éxito de la paz.

Los animadores de esperanza tendrán que afilar juego, danza y risa, apostando por la recuperación y reconstrucción del tejido social, por los ambientes sociales decentes, por la recuperación de los acumulados culturales embolatados en los recodos de la guerra, por la estimulación creativa de actitudes, disposiciones y hábitos de convivencia.

\section{El viaje ${ }^{8}$}

Una influencia significativa para el surgimiento del viaje tiene que ver con una conferencia, en el contexto de un seminario de doctorado en 2003 en la

7. Para ampliar este asunto ver los estudios sobre milicia y escuela en Moreno 2005 y 2009.

8. El viaje como estrategia formativa desde el semillero ha contado con la experiencia viajera y los aportes de metodológicos hechos entre 2008 y 2016 por estudiantado y profesorado del registro PES. 
Universidad de Valencia que ofreció Jorge Larrosa tras invitación del profesor Jaume Martínez Bonafé. Allí, muestra Larrosa un audiovisual artesanal, hecho por él durante un interesante viaje por Tirana con un grupo de estudiantado y profesorado de distintas ciudades europeas en plan de vagabundeo formativo e investigativo. Un grupo cuyos miembros se desconocen entre sí viajan a la ciudad, no van de turismo, ni van muy cómodos. No van tras un objetivo explícito, van a dejarse llevar por la ciudad, por sus habitantes humanos y animales; la recorren captando las prácticas en la ciudad cotidiana. En su disertación valenciana conecta Larrosa la experiencia albanesa de hace ya más de 25 años con la experiencia bourdiana de un viaje «iniciático» del joven sociólogo francés por la desvencijada Argelia a mediados del siglo pasado (La pasión argelina); el viaje por la ciudad transforma.

En Imágenes del desarraigo se ilustra con más de ciento cincuenta fotografías la forma como Bourdieu encara el trabajo de campo y sobre todo su emblemática forma de tomar el pulso en condición de «viajante observador» por un país inmerso en un complejo conflicto (guerra, emigración urbana, desarraigo), referentes para una sensibilidad problematizadora y crítica.

Otro aporte proviene del encuentro con la potente tesis doctoral «situacionista» de Silvia López Rodríguez en la Universidad de Granada. Luego vendrán experiencias de los profesores Martínez Bonafé, Cascante y Estrela Cerveró en el seminario valenciano de trabajo social y otras búsquedas de ciudad a partir de la experiencia viajera. ${ }^{9}$ Gente del vagabundeo, del ocio que siguiendo la potente orientación del flaneur baudelariano (la mirada como actividad), nos animan a la callejeada ociosa y lúdica que pone las cosas y a los seres como sujetos de mirada, reflexión, apropiación y juego. Indagación, deriva, flaneur, vagabundeo por la ciudad y su realidad cotidiana que mueve al viajante desde la experiencia que aporta el viajar.

Ahora en Medellín, en el Instituto Universitario de Educación Física y Deportes de la Universidad de Antioquia, en cursos de grado y posgrado y en el ejercicio investigativo del grupo PES y su semillero, empiezan los viajes por la ciudad un día al semestre desde 2005. En la nave de los viajantes (un viejo

9. Véase interesante abordaje del viaje en Mar Estrela Cerveró y Jaume Martínez Bonafé (2014). 
Chevrolet setenta y cuatro que aún sirve al programa de bienestar de la Universidad), se suben todos (principiantes de carrera, semilleristas del grupo de investigación, pasantes internacionales, habitantes conocedores de ciudad, profesores y estudiantes), casi nunca bajamos de las 50 o 60 personas. El viaje está motivado por una problematización que se ha ido desarrollando al interior del grupo, problematización que define unos presupuestos orientadores para esta práctica pedagógica. A continuación presentamos los más significativos:

- Los futuros maestros y maestras en su proceso de formación deben tener contacto con la ciudad real, ella es su laboratorio, más que la ciudadela laboratorio.

- El viaje extiende el perímetro del aula, la ciudad inquieta desescolariza el conflicto; es asunto de la ciudad que educa.

- El viaje permite trascender la ciudad de la guerra, de la crónica distractora y de la estadística reductora, camino a la humanización de la explicación y la superación cotidianizada del conflicto.

- El viaje es un pasaporte a la ciudad prohibida. La camiseta de la universidad pública da licencia entre fronteras.

- Hay una ausencia de ciudad en la problematización universitaria, las prácticas deben hacerse en contexto social.

- El viaje permite leer las condiciones sociales y humanas bajo las cuales se dan las prácticas LC en la ciudad, permite resignificarlas.

- El currículo tiene poco encuentro con la incertidumbre, se despliega en ambientes controlados.

- Hay una brecha entre el currículo prescrito, de aula, y el currículo en acción social.

- La formación de maestros y maestras es unireferencial (urbana, estratos medios, ciudad pacifica, niñez angelical...).

Tabla 1. Presupuestos del viaje.

\section{Los tres momentos del viaje}

\section{El preactivo}

Sin pretensiones prescriptivas — más motivacionales - cada quien y ante los otros y otras, se pinta en el mapa de la ciudad reconociendo su condición política, social, cultural y ludocorporal; ejercicios de resignificación del lugar ocupado en la urbe a través de preguntas que convoquen a poner la mirada escrutadora sobre puntos que se han hecho paisaje (ejercicio deconstructivo). 


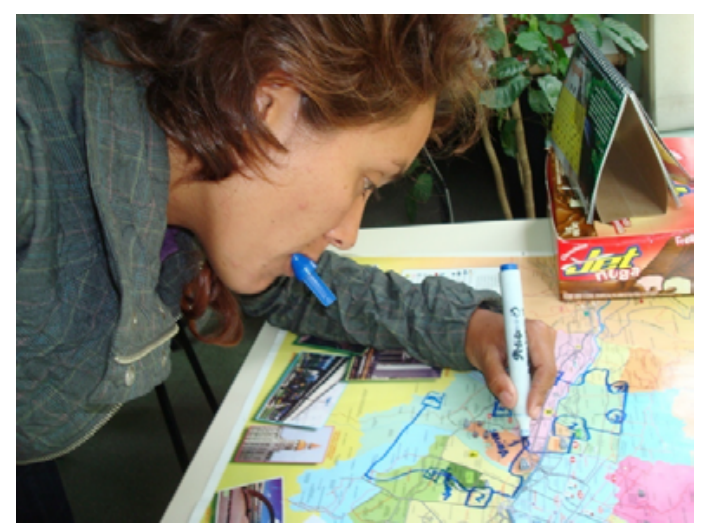

Foto 1. Noreida preparando el viaje.

Esta sensibilización previa al viaje se realiza desde semanas antes, en clase, con estudiantes de primer semestre de la carrera de Educación Física. El viaje es el pretexto que permite configurar una estrategia formativa contextualizada (motricidad/ciudad) de todo el semestre académico. Pretexto para la transversalización docencia/investigación/proyección.

Esta «entrada en situación» va acompañada de: (1) la escucha reflexiva a buen volumen de canciones de ciudad (Calle 13, Cerati, Fito, Versuit Vergarabat, Charly García, Sinatra, Fabulosos Cadillacs, Piazzola, Rubén Blades, Héctor Lavoe, Willy Colón...), de los rapeos en directo desde la memoria corporal inmediata de los participantes; (2) las lecturas iluminadoras de textos de ciudad (Calvino y sus ciudades invisibles, Bourdieu y su viaje, Carlos Calvo, Jaume Martínez Bonafé, Jaume Trilla, sus pensamientos viajeros y sus miradas a los alrededores de la escuela y a los intersticios de la ciudad curricularizada); (3) la construcción de mapas semánticos biográficos y sociobiográficos que conectan vida, territorio y lúdica, maquetas que ayudan a dimensionar la ciudad presente y la ciudad lúdica deseada; (4) reconocimiento de la ciudad histórica (antigua, industrial, ociosa, moderna) a través de películas de contenido problematizador de la cultura urbana en contextos de la proyección educativa de lo corporal (Metrópolis, Percépolis, 1984, Almodóvar, Pasolini, Víctor Gaviria...); (5) la visualización en sitio (y audiovisual) de instalaciones urbanas de expresión corporal (body corp), recortes audiovisuales (ciudades nazis, ciudades del sur y del norte, ciudades lúdicas, ciudades de la guerra, ciudades y no lugares, ciudades grises); (6) lecturas y ejercicios constructivos individualizados o en pequeños colectivos, expuestas a viva voz; (7) la construcción y presentación 
de «maquetas lúdicas» hechas por pequeños subgrupos; (8) referenciaciones de las prácticas (mapeos en papel o en google maps), ejercicios realizados previo reconocimiento de los escenarios, las prácticas y los sujetos en ciudad; (9) reconocimiento temático de las prácticas LC a través de visitas sectoriales que se hacen en los días previos al gran viaje (a la ciclovía, al cerro, a la escuela, a la unidad deportiva de la ciudad). Prácticas que buscan afinar sentidos para el gran viaje.
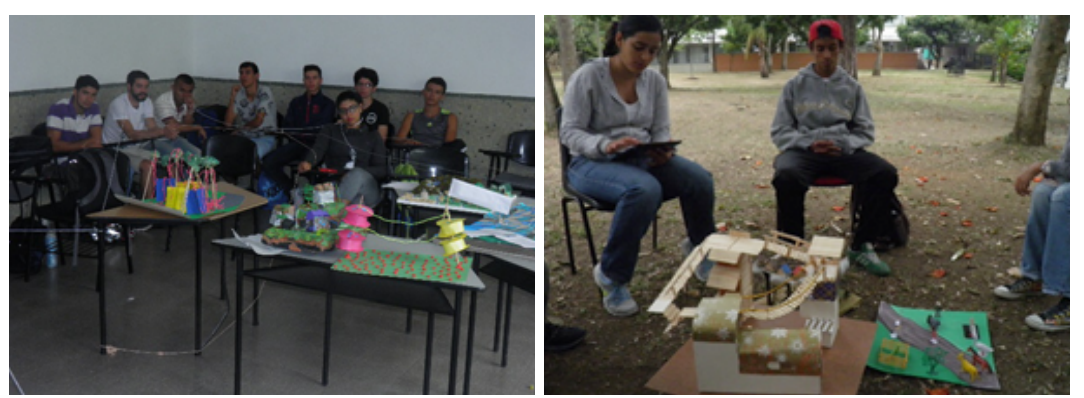

Foto 2 y 3. Ciudad lúdica. Ejercicio preactivo de los viajeros inspirado en Calvino.

Al viaje se llega en cierto estado de embriaguez, a la nave nos subimos ya medio aturdidos. Allí, en los días de la preparación de viaje (deleite antes que baje el telón) se problematiza el campo de la educación, la recreación, el ocio, el deporte y la animación cultural en el contexto de los grandes proyectos de la ciudad (ciudad educadora, ciudad y metro seguridad, área metropolitana, cinturón verde, parques del río, plastificación de las zonas recreativas, deporte y contención social, etc.).

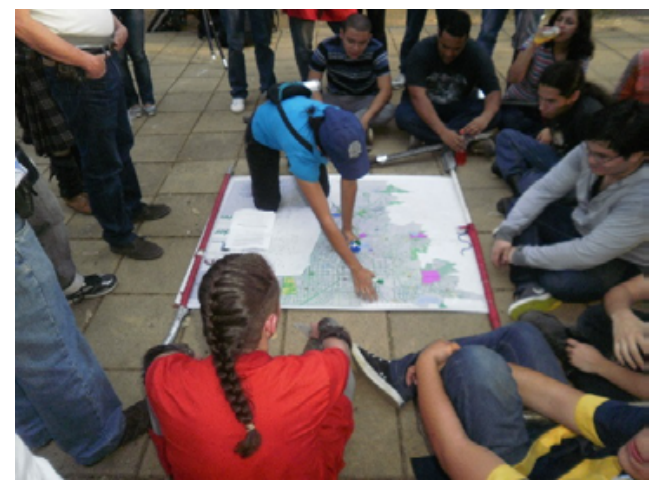

Foto 4. Pintándose en el mapa de la gran ciudad. 


\section{El momento activo}

La nave se abre camino un sábado o un domingo de cada semestre académico entre los barrios y comunas de Medellín. El viejo Chevrolet ronronea por un día entre las 7 a. m. y las 7 u 8 p. m., fatigado y crujiente, desvencijado por los años pero con buen motor, cargado a tope con viajeros ávidos por las faldas y los bajos de la ciudad. Cada semestre «una trayectoria diferente» que se define desde las motivaciones previas y los usos tempo-espaciales en sitio.

Los lugares de parada se establecen previamente (en semillero o en clase/ consenso) o en la marcha en función de la alimentación, el conocimiento y la atracción especial del lugar, de las características del espacio con relación al reconocimiento de prácticas LC; a los sujetos de práctica y los escenarios (a su especificidad, encanto o diversidad). También en función de la condición social y cultural que se da en el lugar: vamos a un elegante club de tenis de la ciudad estrato seis a ver el ritual de un circuito open profesional y a los 10 minutos estamos jugando en un parque de la ciudad marginal en los altos de Guadalupe o parque Gaitán con un grupo de niños «sueltos» ${ }^{10}$. En el camino puede cambiar la dirección, los tiempos, las acciones y los juegos (la corriente en el Valle de Aburrá es incierto).

En el viaje se toma nota, se obtura, pero se trabaja para todos, todos registran para un banco común que reconoce créditos pero es de todos y utilizable por todos.

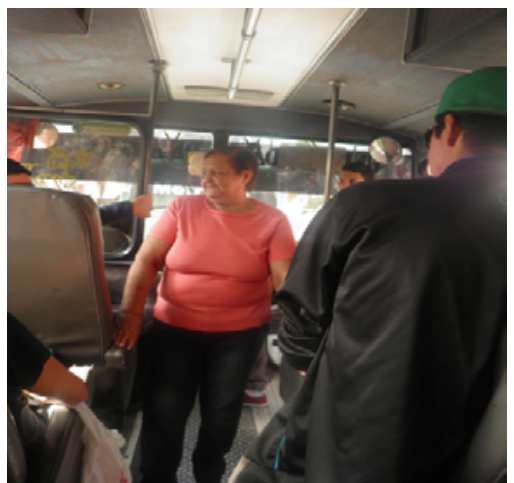

Foto 5. Doña Marta contando la historia de la Comuna 13.

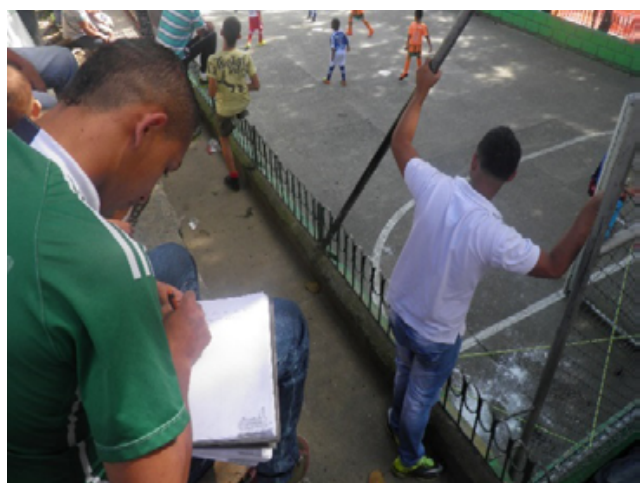

Foto 6. En el momento activo se observa y se registra.

10. A los parques públicos marginales muchos niños van solos o en pequeños grupos, no necesariamente acompañados por sus adultos como en los espacios exclusivos. 


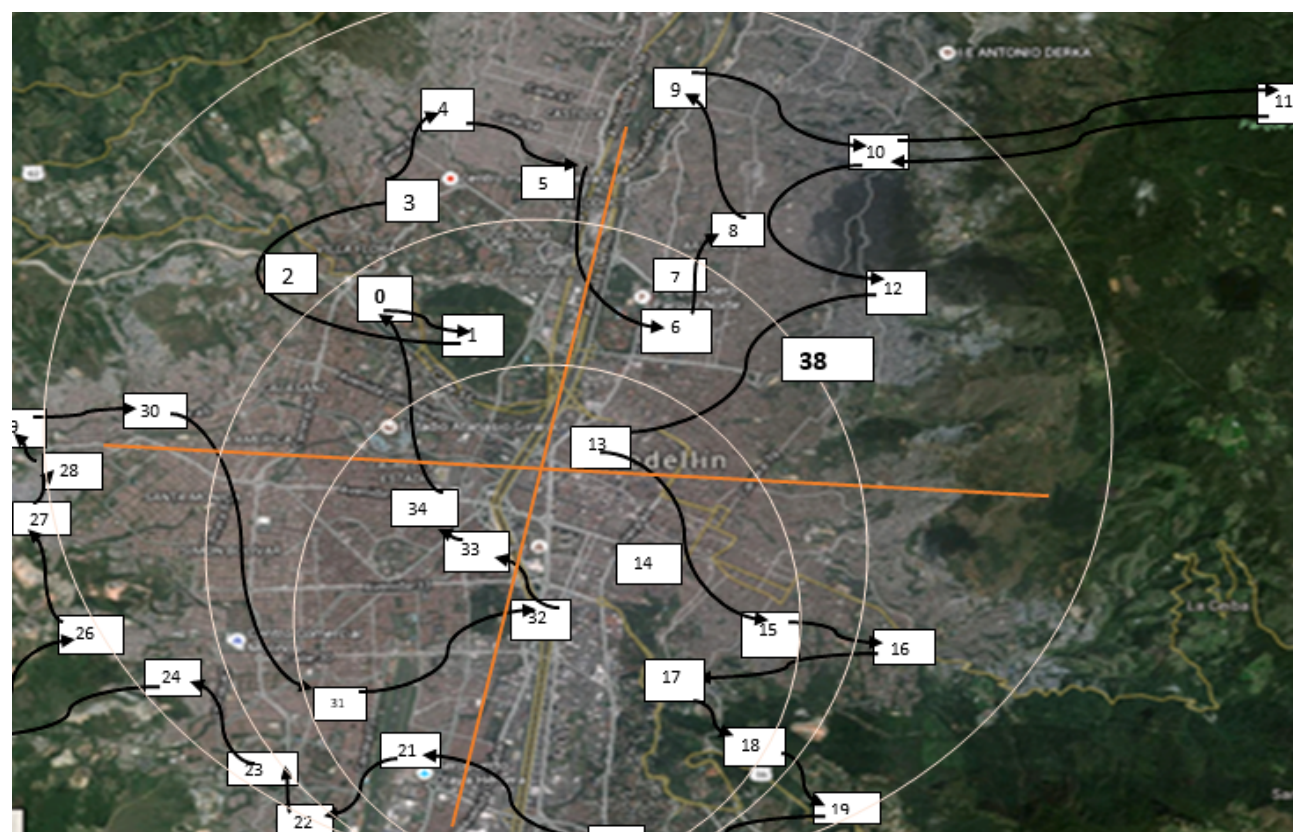

Mapa 1. Los sitios emblemáticos y recurrentes del viaje.

0. Universidad de Antioquia Sede Robledo. Punto de salida. Comuna

I. Cerro el Volador (I600 metros). Comuna

2. Parque Biblioteca La Quintana (Robledo). Comuna

3. Cancha Maracaná (Castilla). Comuna

4. Unidad Deportiva Rene Higuita (Castilla)

5. Parque Recreativo Juanes de la Paz (Castilla)

6. Universidad de Antioquia Sede Central. Comuna

7. Complejo recreativo científico y cultural norte

8. Parque el Calvario. (Campo Valdez). Comuna

9. Estación Madera. Comuna

10. Parque Biblioteca España (Santo Domingo). Comuna

II. Parque Arví

12. Raizal (La Cruz). Balcón de los artistas. Comuna

13. Parque Bolívar (Centro de la ciudad). Comuna

14. Museo de la Memoria

15. Parque Recreativo La Ladera (Caicedo). Comuna

16. UVA Sol de Oriente y Cinturón Verde
17. Parque la Milagrosa

18. Hotel intercontinental

19. Centro Comercial el Tesoro

20. Club Unión

21. Unidad Deportiva María Luisa Calle

22. Parque de la Mota

23. Unidad Deportiva Belén Rincón

24. Loma de los Bernal

25. Cerro de las tres cruces

26. Zafra

27. Universidad de Medellín

28. Parque los Alpes

29. La escombrera

30. Parque de la Floresta

31. Unidad Deportiva Belén Rosales

32. Cerro Nutibara, Circo Medellín. Comuna

33. Unidad Deportiva de Belén Andrés Escobar

34. Universidad Pontificia Bolivariana y Carrera 70

35. Unidad Deportiva Atanasio Girardot

36. Comuna 16 (Belén)

37. Itagüí

38. Instituciones educativas D\&C

39. Caldas (parques y escuelas)

Convenciones numeradas. 
Cada viajante se asoma a la ciudad (paisaje) desde su propia subjetividad, escoge previamente o sobre la marcha, individual o colectivamente un foco sobre el cual interesarse, sobre el cual obturar; unos van tras los viejos, otros tras las mujeres jóvenes, algunos se interesan por los deportistas, por los niños juguetones, por los malabaristas del semáforo, por los jóvenes con perros, otros van tras los sonidos musicales diferenciando los gustos de los citadinos, otros tras los olores de los mecatos domingueros de parque. Los participantes se disputan el pasacintas o el porta memoria y la silla de atrás; desde allí se prende el goce que a veces estorba a los que van en plan total de registro, no faltan los reclamos, algún trasnochado duerme y solo despierta en las «estaciones». No falta quien se haya perdido en una de las paradas y no alcance el despegue de la nave.

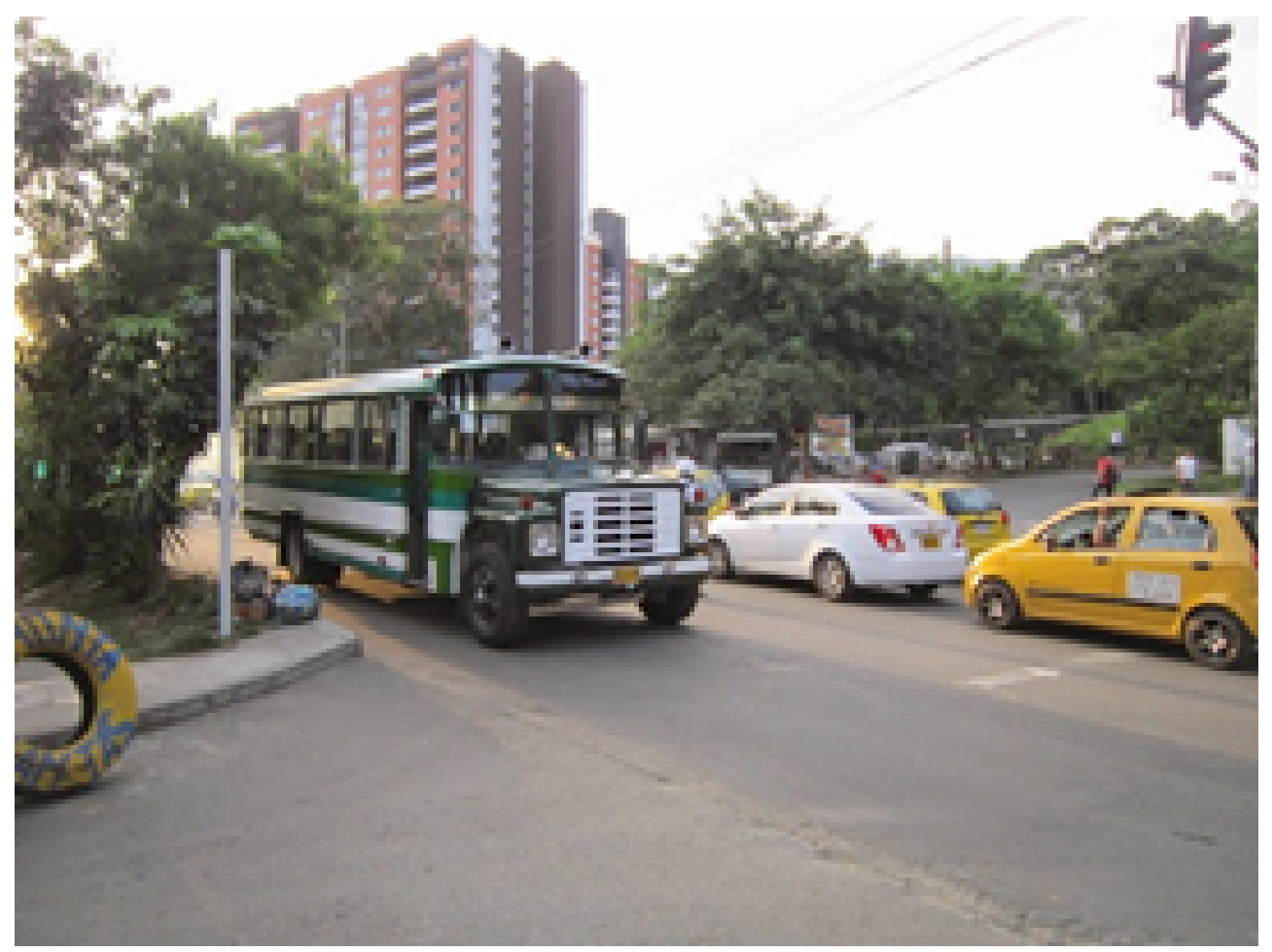

Foto 7. La nave penetra las entrañas de la ciudad. Autor: Luis Fernando Bermúdez.

En el recorrido nos ha pasado de todo menos una apagada de motor. Una parada obligada por el cortejo custodiado de un don de la falda, una persecución policial, un choque, un motociclista en el suelo, una rumba, unos chicos 
que nos invitan o se dejan invitar a jugar a un picao, una caseta de chunchurria barata, un silencio sepulcral ante una descripción dramática de un testigo histórico, un acelerón obligado por la inquietud controlante de un vigilante de centro comercial, una mirada cómplice entre jóvenes ligando, un despiste, una roncada, un daño de estómago.

\section{El momento posactivo}

Es el que más dura y el que más ribete «académico» posee. Generalmente se utiliza el salón y la sala de computadores. Se organiza la base de información de la salida, se evalúa, se realiza taller para levantar preguntas problemáticas desde las fotos y videos, también desde los recuerdos o las anotaciones de libreta hechas durante el recorrido a partir de una revisión colectiva de los registros. Luego vendrán sesiones de exposición de las problematizaciones individuales o subgrupales resultantes, actividad que pueden llevar a un proyecto investigativo, a un trabajo de fin de grado o a una tesis de posgrado.

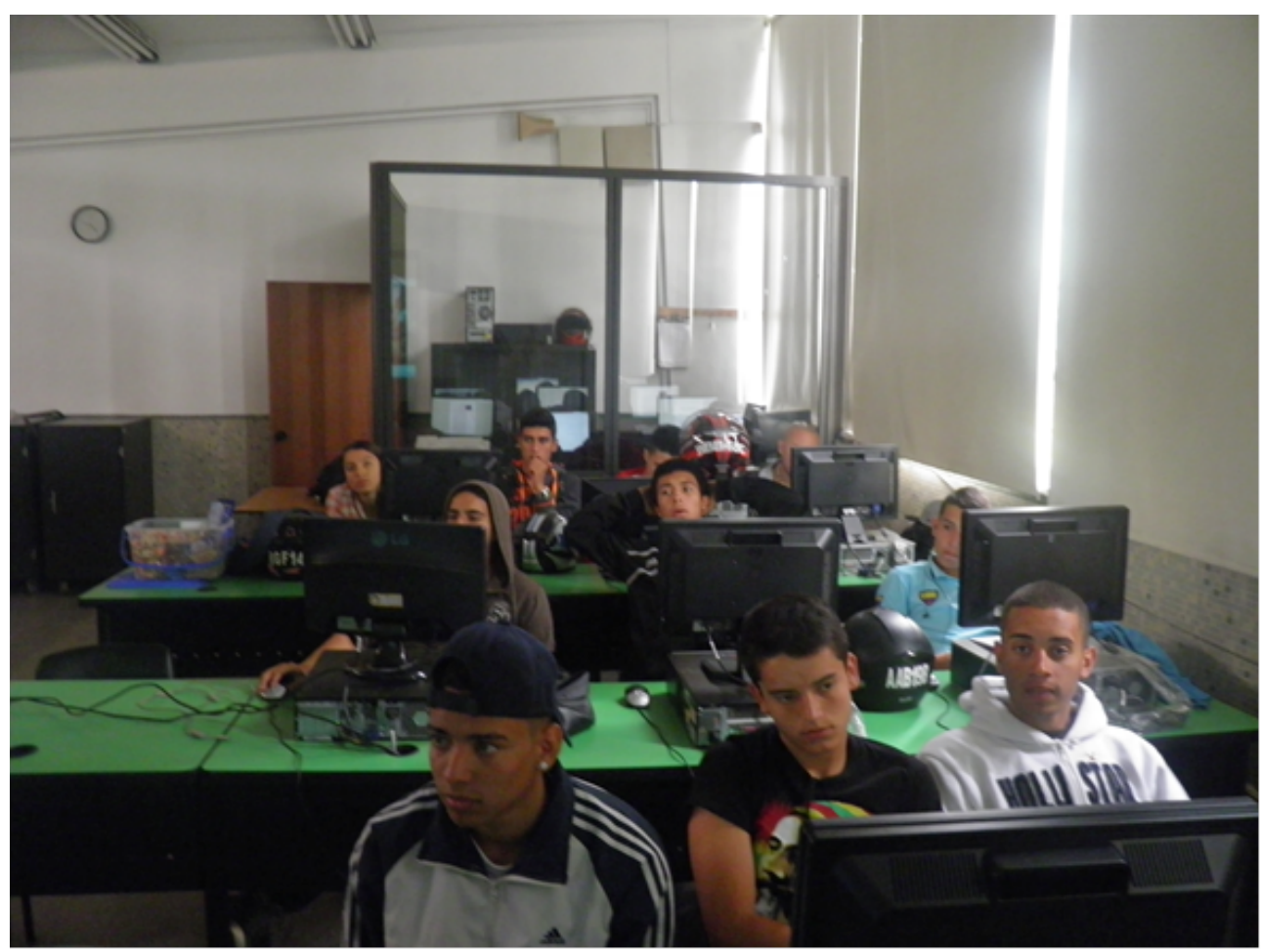

Foto 8. Sistematizando y problematizando registros del viaje. 
Zeichner (1982) citado por Popkewitz (1994) indica que «debido a las estrechas relaciones que existen entre la escuela y el contexto social, político y económico en que está inmersa, cualquier consideración de las consecuencias que se deriven de la acción en el aula, debe ir más allá de los límites de la clase e incluso de la escuela». Así, en este tercer momento de la estrategia viajera, el acto reflexivo vincula las «apreciaciones de campo» al terreno del entendimiento formativo e investigativo, como paso necesario al terreno de la reconfiguración conceptual del «recorte de realidad» que permite la marcha por la ciudad.

El viaje es una estrategia que parte de una visión dinámica de la investigación formativa en la universidad, que dimensiona las limitaciones del entre muro universitario para la formación de un educador corporal situado histórica, social y culturalmente.

El viajante desde la experiencia estética del viaje confronta su potencial sensible para percibir y cuestionar sucesos, actos, expresiones, hechos y situaciones que entrega la ciudad educante. Desde allí se confronta, se interpela y en ese sentido se abre social y culturalmente en este «no lugar escolar» pero educativo. Los escenarios de ciudad se convierten en una opción para pensar el significado de la tríada: escenario, práctica y sujeto en la conformación de un potencial didáctico situado. Allí, en el recorrido, tocados por los descubrimientos y la incertidumbre se significan y resignifican lugares y no lugares, territorios y mapas; referencia de la ciudad como opción educadora. Se busca sentido y horizonte al campo, a sus prácticas, teorías, creencias, compromisos y proyecciones.

\section{Lo que va a ser ya viene siendo}

El viaje es una iniciación, una sensibilización de estudiantes, maestros jóvenes e investigadores en el drama de la ciudad, sobre todo en el drama de los niños, en sus afanes, en su cotidianidad, bajo la motivación de que la universidad pública tiene un compromiso con los sectores más vulnerados, marginados e invisibilizados. Ir desarrollando sentido de aquellas prácticas, de aquellos territorios sobre los que potencialmente se desplegará el futuro profesional del investigador social y el educador. Este viaje también busca 
encontrar sentido a esas prácticas que tienen un potencial educativo transformador, generalmente invisibilizadas y marginadas por la educación hegemónica.

Kristian Herbolzheimer, director de los Programas Colombia y Filipinas de Conciliation Resources, resaltaba en evento organizado por el Instituto Catalán Internacional para la Paz que «Colombia viene construyendo paz desde muchos otros espacios: académico, social, institucional, económico... y que todos los actores serán imprescindibles para esa construcción de la paz. En definitiva: hay que identificar, reconocer y recorrer los múltiples caminos hacia la paz» sobre todo diríamos reconocer lo que ya se está siendo a partir de los acumulados sociales, humanos, profesionales, experienciales, institucionales y no institucionales, formales y no formales con potencial posconflictual. Cuestión social deseada que es responsabilidad de toda la sociedad.

En su investigación sobre las vías de la educación, Hargreaves y Shirley $(2009,2012)$ rechazaron el supuesto de diseñadores de políticas como sujetos con conocimientos implícitos de aquello que es mejor para las escuelas y sistemas educativos; plantearon que muchos de los desarrollos más positivos en educación hoy en día suceden, no tanto debido a sino a pesar de muchas políticas educacionales y de muchos burócratas. Según se desprende de su investigación en tres países latinoamericanos (Chile, Brasil y Colombia) la investigación educativa podría explorar el cambio desde varios puntos de vista. Podría hacerse desde experiencias de «educación de nueva vía», también llamada una educación otra o una alternativa que ya viene sucediendo en lugares insospechados para los burócratas. Para el caso, El viaje, es una experiencia reveladora que descubre, más allá de las distracciones de la educación gris y estandarizada, trazos de educaciones otras en callejas de la gran ciudad.

\section{Desplazamientos experienciales: trazos de una educación ludocorporal otra}

El desafío para la educación es grande en el actual contexto de crisis de la ciudad. Infante Márquez (2011, pág. 229) expresa que la educación (tra- 
dicional escolar) tiene un gran potencial para favorecer un conflicto violento, el sistema educativo, enfatiza, se encuentra estrechamente relacionado con el conflicto, pues este sistema reproduce relaciones, actitudes, disposiciones y habilidades convenientes para las clases que están en el poder. Por su parte Calvo Muñoz (1987) sugiere hacer una diferenciación entre el alcance de la educación (mundo de relaciones posibles) y los límites de la escolarización (mundo de relaciones preestablecidas). La educación, posiblemente en los márgenes de la formalidad y en los territorios de la informalidad, ofrece ya opciones y rutas para una educación otra.

La educación deseada está incubada en la distrópica ciudad que nadie quiere vivir, allí se está disoñando de la mano de gente de otraparte y de otredad que viven entre nosotros. Experiencias emblemáticas de una educación y una ciudad otra que ya viene siendo desde sus fisuras y sus márgenes. Panorama de prácticas emblemáticas de una educación ludocorporal urbana que se sale de la órbita institucional formal; reflejo de posibilidades de una educación corporal otra que la ciudad nos va mostrando sutilmente a lo largo del viaje. El viaje permite identificar en las prácticas un campo (una educación otra), pueden detectarse: regularidades entre los agentes y las agencias, actitudes y disposiciones de los participantes, liderazgos, sometimientos; opciones emblemáticas para promover prácticas o formas de vida en la ciudad no reducidas al deseo o la intención político-hegemónica.

A continuación se presenta una selección de prácticas LC representativas de lo que denominamos trazos de una educación otra que ya está sucediendo, invisibilizadas por prácticas hegemónicas. 


\begin{tabular}{|l|l|}
\hline Estación de viaje & $\begin{array}{l}\text { «Balcón de los artistas» Viaje maestrandos Viaje con estudiantes de pregrado y } \\
\text { semillero }\end{array}$ \\
\hline $\begin{array}{l}\text { T/E. Sujetos de } \\
\text { investigación }\end{array}$ & $\begin{array}{l}\text { 2015. Comuna 3, Manrique oriental (La Cruz, Raizal). } \\
\text { Niños, niñas y jóvenes (NNJ) artistas danzantes }\end{array}$ \\
\hline Descripción & $\begin{array}{l}\text { Viajando por Manrique oriental, un chico con el que topamos en la Unidad Deportiva } \\
\text { nos conduce a un lugar de un barrio alto y límite de la ciudad (estrato 1 y 2) donde } \\
\text { funciona una compañía de danza urbana; la Corporación Mandala nos pone en contacto } \\
\text { con sus pioneros. }\end{array}$ \\
\hline Proyección & $\begin{array}{l}\text { Referente para promover superficies investigativas Maestría Motricidad y Desarrollo } \\
\text { Humano (U de A) }\end{array}$ \\
\hline Participantes & $\begin{array}{l}\text { Estudiantes de maestría e integrantes de semilleros de investigación y coordinadores de } \\
\text { los grupos de investigación del Instituto Universitario de Educación Física. } \\
\text { Se proyecta convenio PES / Mandala }\end{array}$ \\
\hline Lo social y lo insti- \\
tucional & $\begin{array}{l}\text { Prácticas de animación corporal y arte (educación no formal y arte). Compañía Balcón } \\
\text { de los artistas. Maestría Universidad de Antioquia. } 5 \text { grupos de investigaciónuniversita- } \\
\text { rios, Corporación Mandala por la Vida y el Territorio. }\end{array}$ \\
\hline Compromiso & $\begin{array}{l}\text { Liderazgo cultural familiar con comunidades marginales de Medellín. } \\
\text { Reconocimiento de prácticas LC no integradas a la red oficial. Iniciativas barriales exi- } \\
\text { tosas con presencia nacional e internacional. Conocimientos prácticos en la formación } \\
\text { de base. }\end{array}$ \\
\hline Registro & \multicolumn{1}{c}{ as } \\
\hline
\end{tabular}

\begin{tabular}{|l|l|}
\hline Estación de viaje & «Circo Medellín» \\
& $\begin{array}{l}\text { Viaje con grupo de investigación PES/Observatorio INDER. Viaje con grupo de } \\
\text { investigación y estudiantes en formación. }\end{array}$ \\
\hline $\begin{array}{l}\text { T/E. Sujetos de } \\
\text { investigación }\end{array}$ & $\begin{array}{l}\text { 2013. Comuna 16, Belén (Cerro Nutibara). Bajos del Cerro Nutibara. Maestros, artistas } \\
\text { y jóvenes artistas circenses }\end{array}$ \\
\hline Descripción & $\begin{array}{l}\text { Un grupo de proyecto PES/INDER se adentra en la experiencia de circo urbano que } \\
\text { lidera uno de los pioneros de los años 70 y } 80 \text { del teatro popular y de compromiso de la } \\
\text { ciudad. Heredero de una avanzada social pastoral de un sacerdote español con jóvenes } \\
\text { marginados de la comuna X que hoy son artistas de la compañía Circo Medellín. }\end{array}$ \\
\hline Proyección & $\begin{array}{l}\text { Se desarrolla una investigación: «Las prácticas LC como dispositivos configuradores } \\
\text { del entramado social de la ciudad de Medellín 2013-2014». }\end{array}$ \\
\hline Participantes & $\begin{array}{l}\text { Grupo de proyecto: } \\
\text { Universidad de Antioquia y Observatorio del Instituto de Deporte } \\
\text { de Medellín (INDER). } \\
\text { Financia INDER }\end{array}$ \\
\hline
\end{tabular}




\begin{tabular}{|l|l|}
\hline $\begin{array}{l}\text { Lo social y lo insti- } \\
\text { tucional }\end{array}$ & $\begin{array}{l}\text { Prácticas de animación cultural (educación no formal y arte). Universidad de Antioquia, } \\
\text { INDER Medellín, Corporación Circo de Medellín, estudiantes en formación de pregra- } \\
\text { do y posgrado, Semillero PES. }\end{array}$ \\
\hline Compromiso & $\begin{array}{l}\text { Reconocimiento de prácticas LC en función de la calidad del entramado social de la } \\
\text { ciudad. } \\
\text { Prácticas LC no hegemónicas de proyección social popular. Saberes prácticos en la } \\
\text { animación cultural. }\end{array}$ \\
\hline Registro &
\end{tabular}

\begin{tabular}{|l|l|}
\hline Estación de viaje & «El Picao» Viaje por Medellín con estudiantes de pregrado y \\
Semillero PES.
\end{tabular}




\begin{tabular}{|c|c|}
\hline Estación de viaje & «Juegos recreativos tradicionales de la calle (Caldas, Antioquia)» \\
\hline $\begin{array}{l}\text { T/E. Sujetos de } \\
\text { investigación }\end{array}$ & $\begin{array}{l}\text { 2005-2015. Caldas (parques, calles, escuelas, auditorios, veredas). Jornadas de juego y } \\
\text { academia, toma universitaria, prácticas universitarias }\end{array}$ \\
\hline Descripción & $\begin{array}{l}\text { Viajando por el Valle de Aburra (Itagüí, Caldas, Guayabal) nos encontramos en Caldas } \\
\text { Antioquia con una «buena práctica» en } 2008 \text { para adelantar un macro proyecto investi- } \\
\text { gativo con universidades de Brasil y Argentina. }\end{array}$ \\
\hline Proyección & $\begin{array}{l}\text { Se desarrolla un macroproyecto «Juegos de la calle una buena práctica referenciable en } \\
\text { los procesos de la educación del cuerpo en Colombia» con cinco investigaciones (dos } \\
\text { tesis de maestría y tres como tesis de grado). }\end{array}$ \\
\hline Participantes & $\begin{array}{l}\text { Estudiantes de pregrado y posgrado, semillaristas PES, funcionarios públicos, profeso- } \\
\text { rado. }\end{array}$ \\
\hline $\begin{array}{l}\text { Lo social y lo insti- } \\
\text { tucional }\end{array}$ & $\begin{array}{l}\text { Juego recreativo tradicional, CODI; INDEPORTES Antioquia; INDERC, Secretaría de } \\
\text { Educación de Caldas, CNPQ (Brasil), Coldeportes, universidad, centro de prácticas. }\end{array}$ \\
\hline Compromiso & $\begin{array}{l}\text { Reconocimiento de un evento lúdico popular de origen en intereses de compromiso } \\
\text { social del profesorado que cuenta con algo más de } 35 \text { años. Reconocimiento de prácti- } \\
\text { cas tradicionales en sitio. }\end{array}$ \\
\hline Registro & \\
\hline
\end{tabular}

\begin{tabular}{|c|c|}
\hline Estación de viaje & «Mil espadas» \\
\hline $\begin{array}{l}\text { T/E. Sujetos de } \\
\text { investigación }\end{array}$ & $\begin{array}{l}\text { 2009. Comuna } 16 \text { (Belén). Parque Villa de Aburrá. Instructores, colegas, padres, ma- } \\
\text { dres niñas y jóvenes guerreros }\end{array}$ \\
\hline Descripción & $\begin{array}{l}\text { Viajando por Medellín con el grupo de pregrado y semillero o con el grupo de proyecto } \\
\text { de investigación (proyecto INDER), nos encontramos con un grupo grande de jóvenes } \\
\text { que ataviados con «ropas medievales» y en medio del temor inicial de los habitantes } \\
\text { del barrio Belén, consolidan un «juego luctatorio» de sentido medieval y tradicional en } \\
\text { Medellín. }\end{array}$ \\
\hline Proyección & $\begin{array}{l}\text { Motiva interés investigativo del grupo por las prácticas luctatorias, militares, guerrearas } \\
\text { (...) } \\
\text { Por las formas y sentidos de apropiación de prácticas lúdicas extranjeras y de conno- } \\
\text { tación guerrera. Por la investigación de prácticas LC en conexión con la clase social y } \\
\text { divulgación mediática. }\end{array}$ \\
\hline Participantes & $\begin{array}{l}\text { Estudiantes de pregrado, Semillero PES, Grupo de proyecto PES/INDER Medellín, } \\
\text { corporación, club, empresa. }\end{array}$ \\
\hline $\begin{array}{l}\text { Lo social y lo insti- } \\
\text { tucional }\end{array}$ & $\begin{array}{l}\text { Prácticas LC de los jóvenes de estratos sociales altos de la ciudad, clase social, parques, } \\
\text { alcaldía, espacio público. } \\
\text { Diseñadores de armas e indumentaria, cultores de arte y lúdica medieval. Combatientes. }\end{array}$ \\
\hline Compromiso & $\begin{array}{l}\text { Reconocimiento de una práctica ludocorporal que reúne a un importante grupo de jóve- } \\
\text { nes de clase media y alta de la ciudad, reconocimiento de saberes prácticos en sitio. }\end{array}$ \\
\hline
\end{tabular}




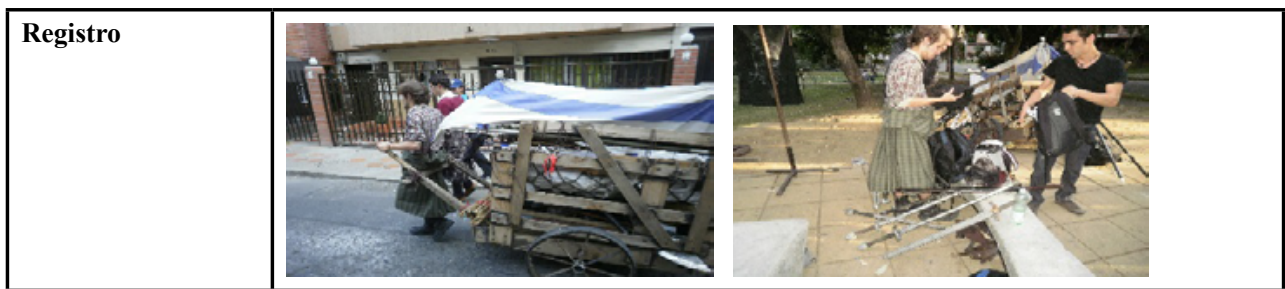

\begin{tabular}{|l|l|}
\hline Estación de viaje & «El viejo caddie» \\
\hline $\begin{array}{l}\text { T/E. Sujetos de } \\
\text { investigación }\end{array}$ & 2012. Comuna 16, Belén Rincón. Familia, habitantes, NNJ, instructores \\
\hline Descripción & $\begin{array}{l}\text { Viajando por Medellín con el grupo de investigación PES/INDER y estudiantes en } \\
\text { formación nos encontramos con un representante de los caddie de los clubes de la bur- } \\
\text { guesía medellinita de mitad de siglo xx, una función de los niños del barrio que ya no } \\
\text { existe más, pioneros de una práctica deportiva apropiada de la burguesía hacia un barrio } \\
\text { popular (extinguida). }\end{array}$ \\
\hline Proyección & $\begin{array}{l}\text { Motiva interés investigativo por la pertinencia histórica, social y económica de las } \\
\text { prácticas LC de la ciudad. }\end{array}$ \\
\hline Participantes & Especuladores de tierras, semilleristas, investigadores, habitantes, desplazados. \\
\hline $\begin{array}{l}\text { Lo social y lo insti- } \\
\text { tucional }\end{array}$ & $\begin{array}{l}\text { Club, barrio, constructoras, alcaldía, urbanizadoras, clase social, burguesía medellinita } \\
\text { (enclaves lúdico deportivos), sectores populares de Belén. }\end{array}$ \\
\hline Compromiso & $\begin{array}{l}\text { Reconocimiento de una práctica deportiva barrial en extinción (golf) por presión de los } \\
\text { urbanizadores y el descontrol del espacio público urbano (historia de empoderamientos } \\
\text { lúdicos públicos inconclusos), saberes prácticos en sitio. }\end{array}$ \\
\hline Registro & \\
\hline
\end{tabular}

\begin{tabular}{|l|l|}
\hline Estación de viaje & «Rosa Barranca» \\
\hline $\begin{array}{l}\text { T/E. Sujetos de } \\
\text { investigación }\end{array}$ & $\begin{array}{l}\text { 2012. Comuna 16, Belén Rincón. Líderes y lideresas populares, NNJA, instructores, } \\
\text { políticos }\end{array}$ \\
\hline Descripción & $\begin{array}{l}\text { Derivando por Belén con el grupo de investigación PES/INDER y estudiantes nos } \\
\text { encontramos con una mujer que convirtió su casa en espacio ludorecreativo popular, } \\
\text { sus hijas en instructoras; su vida social en vocación de servicio y referente para la vida } \\
\text { política y recreativa barrial. }\end{array}$ \\
\hline Proyección & $\begin{array}{l}\text { Motiva interés investigativo por los sentidos de la calidad del entramado social por la } \\
\text { vida ludorecreativa; por el lugar de las mujeres en la política institucional, barrial y } \\
\text { comunitaria. Por la red institucional de la política comunitaria. }\end{array}$ \\
\hline Participantes & $\begin{array}{l}\text { Lideresas barriales y comunitarias lideres deportivos, mediadores barriales de las prácti- } \\
\text { cas ludo recreativas institucionales y no institucionales, políticos, funcionarios públicos. }\end{array}$ \\
\hline
\end{tabular}




\begin{tabular}{|l|l|}
\hline $\begin{array}{l}\text { Lo social y lo insti- } \\
\text { tucional }\end{array}$ & $\begin{array}{l}\text { Club comunitario, casa comunitaria, institución barrial, nodos institutos oficiales y } \\
\text { comunidad, INDER, alcaldía, animadores culturales INDER, organizaciones barriales. }\end{array}$ \\
\hline Compromiso & $\begin{array}{l}\text { Reconocimiento de una práctica comunitaria legítima, con reconocimiento social barrial } \\
\text { e institucional/alcaldía. Reconocimiento de saberes prácticos en sitio. }\end{array}$ \\
\hline Registro &
\end{tabular}

\begin{tabular}{|c|c|}
\hline Estación de viaje & «Los chicos de aguas frías» \\
\hline $\begin{array}{l}\text { T/E. Sujetos de } \\
\text { investigación }\end{array}$ & 2012. Comuna 16. Belén Rosales. Niños de los semáforos \\
\hline Descripción & $\begin{array}{l}\text { En la marcha por Belén, comuna de } 200.000 \text { habitantes, encontramos en el semáforo de } \\
\text { Betlemitas a un grupo de niños y jóvenes malabaristas que se rotan entre la presenta- } \\
\text { ción, la práctica y el taller de construcción de la herramienta. La barranca donde están } \\
\text { establecidos muestra huellas de su diaria permanencia. }\end{array}$ \\
\hline Proyección & $\begin{array}{l}\text { Permite identificar prácticas LC urbanas no referenciadas. Los jóvenes apuestan a una } \\
\text { lúdica de subsistencia o supervivencia. Puede ser buena parte de la chiquillada del } \\
\text { pueblo que no tiene acceso a la escuela ni a los programas de la alcaldía. }\end{array}$ \\
\hline Participantes & $\begin{array}{l}\text { NNJA de la ciudad que establecen grupos de práctica y exhibición circense; malabares } \\
\text { hechos generalmente con instrumentos que ellos mismos confeccionan. }\end{array}$ \\
\hline $\begin{array}{l}\text { Lo social y lo insti- } \\
\text { tucional }\end{array}$ & $\begin{array}{l}\text { Espacios de exhibición temporalizados por el semáforo (ajuste ludocorporal al ritmo de } \\
\text { la ciudad). } \\
\text { Territorios apropiados por NNJA en función de sus filiaciones y negociaciones de fuerza } \\
\text { o consenso. } \\
\text { Técnicas LC globalizadas (circo urbano, malabares callejeros, flujos de jóvenes calleje- } \\
\text { ros por las grandes ciudades). Grupos y culturas juveniles. }\end{array}$ \\
\hline Compromiso & $\begin{array}{l}\text { Reconocimiento de prácticas LC que definen redes de actuación en la ciudad. Cono- } \\
\text { cimientos y técnicas LC que se trasmiten de generación en generación de chiquillada } \\
\text { callejera. Entre arte urbano y actividad de exhibición técnica de supervivencia. }\end{array}$ \\
\hline Registro & \\
\hline
\end{tabular}

Tablas 2,3,4,5,6,7 y 8. Prácticas lC emblemáticas de una educación otra en el área metropolitana del Valle de Aburrá (Antioquia). 
Algo mueve a Rosa Barranca, a la bailarina de la compañía del balcón de los artistas, a Carlos Álvarez y colegas del circo Medellín, al alfarero Heriberto, a don Jaime el persistente [...], algo distinto muy energético que los hace incluso negarse a recorrer los caminos que lo social les tiene predestinado. $\mathrm{Y}$ ese algo tiene significado para la reflexión de educadores en formación.

\section{A manera de cierre}

Lo común en ellos y en ellas, sujetos participantes de la experiencia o la práctica emblemática, es el estar atrapados e implicados en el juego social, lo acepten o no; se enmarcan en él, hacen parte de sus clasificaciones o se diferencian en tanto «sujetos de derecho» y con derecho. Su participación es diferenciada y diferenciable según la posición ocupada en el campo respectivo de la práctica (recreación, salud, trabajo, deporte, educación) y según la trayectoria seguida hacia la posición que se llegue a ocupar en la ciudad (niño, negra, inmigrante, perseguido, desaparecida, manipulado, invisibilizada, desplazada...).

En la ciudad el sujeto hace parte de un sistema estructurado y no estructurado de prácticas y expresiones leíbles y enmarcables (véase Bourdieu y Waqcuant 2005). Allí las expresiones situadas, cinesias, kinemas, culturemas que dan sello desde el cuerpo y con el cuerpo. La movilidad posible dentro del campo donde se actúa, su dinamicidad en él, define el potencial de participatividad real; se puede saber de qué va el cuerpo en la apuesta a punta de la lectura de la retórica y la dramática del enunciado corporal en contexto de su despliegue social educativo.

Los intereses son diversos, pero todos se ven y se van a una; Malena, Águeda, el caleño maestro, el bailarín de elite, el adolecente, el chico artista, la madre acompañante incansable, el psicólogo social de la ong que acompaña a la compañía en su proceso de constitución formal y social, el barrio, la federación; estatalizados o «desestatalizados» se apuntan a la movida, hay una energía motriz que define la fuerza de los intercambios estéticos, de los intercambios educacionales. 
Mientras la escuela del frente está vacía, el espacio «medianamente institucionalizado» del artista emergente o del espacio de la recreación comunitaria está lleno. Los habitantes van a este lugar (que es no lugar) como ir de fiesta; a la escuela, aún, se va como se va al presidio. La escuela sigue incólume pero cruje con la illusio que se respira y transpira en estos «no lugares». El sistema escolar, el Estado, la iglesia, los partidos políticos o los sindicatos no son aparatos sino campos (Bourdieu y Waqcuant 2005); son espacios de juego, hay un producto incorporable, encarnable bajo cierto régimen, que está en juego.

Especie de prácticas de esperanza que se juegan en los sentidos de poder que se concretan en los intercambios a partir de las filiaciones mismas que se configuran y reconfiguran dinámicamente en las líneas de fuerza que se definen en el contexto de lo social. A eso se va allí también; solo que no siempre en estado de consentimiento, a veces en estado de resistencia, de diferenciación, de rechazo, de reclamo, de deslocalización.

Nace una inquietud desde el viaje por la comuna. En la bailarina, como en cualquiera de los otros agentes, se deja ver la illusio... cuál es la illusio que hay en esta gente para participar con tanta fuerza, para ser atraídos, atrapados con tanto imán en la acción danzaria, lúdica, deportiva o recreativa; inquietud por aquello que los mueve, anima y transforma en actores de primer orden para una illusio mayor, una educación otra, una sociedad otra.

El interés, desde una analítica social, no se reduce a lo material. Hay tantos tipos de interés como campos sociales y cada espacio social posee capitales que se cultivan (corporales, simbólicos, materiales); se define allí una motivación económica, política, cultural, corporal y deportiva. Poder, triunfo, enriquecimiento, distinción, afanes de la constitución de un dulce régimen que se juega en y con el cuerpo. Es así como Bourdieu propone sustituir el término interés por el de illusio. Se percibe en los participantes y en los espectadores de nuestra selección cartográfica una movilización social cuyo talante energético está definido por los sueños de aquellos que menos opción tienen para hacerlos realidad (dada la disputa de intereses en los regímenes del juego oficial y hegemónico). En su interior hay la posibilidad de «valori- 
zar las especies de capital que se poseen» (Bourdieu y Waqcuant 2005), que se constituyen, que se expresan en la calle.

La educación, el arte, el deporte, la recreación y la cultura tienen arraigo y potencial necesario para favorecer o no el desarrollo de lenguajes, talantes, actitudes y disposiciones diferentes a la violencia desbordada; ello en función de las fuerzas que movilizan los que juegan. Esas expresiones corporales presentan más o menos potencial de experimentación de formas lúdicas e inteligentes de convivencia o de conflicto. La guerra ha dejado un lastre pesado en las generaciones jóvenes que la escuela puede tomar como foco de atención, de apalabramiento sensible y ético político de los conflictos escolares y sociales en sus diversas manifestaciones como ruta para superar drama social.

El arte, el deporte, el juego y la recreación enamoran a los jóvenes y están conectados con representaciones, imaginarios y con habitus que pueden favorecer la vida en condiciones de legitimidad, legalidad y eticidad. Pueden favorecer, como ya lo hacen, el impulso de una sociedad decente.

Aspirar a una sociedad sin conflictos nos presenta como románticos e ilusos. La educación y el arte pueden inscribirse en la ardua tarea de generar ambientes sociales democráticos, dignos y conviventes. Las prácticas educativas pueden apostarle a una formación para vivir en los contextos de la conflictividad y la confrontación por las vías del respeto, la participación y la inclusión de todos y todas.

El camino social a transitar es un asunto que compete a todos y todas, las prácticas educativas formales y no formales, institucionalizadas y no institucionalizadas son baluarte histórico y político potencial de esta aspiración. En ese sentido coincidimos con quienes entienden el postconflicto como una fase de transición que sigue a los acuerdos de paz, en la cual, el desafío más importante es crear o fortalecer las prácticas y las acciones requeridas para que la violencia con connotaciones políticas perversas no vuelvan a ejercerse brutalmente contra la población civil, en este caso contra NNA, que reclaman espacio a través de la expresión ludocorporal misma para hacerse personas; posibilidad de presente y futuro de lo que aún se llama Colombia. 


\section{Referencias}

Arriagada Zubieta, R. (2007). «El concepto de flaneur en A partir de Manhattan de Enrique Lihn». Proyecto Patrimonio. En: http://www. letras.s5.com/el150207.htm

Baudelaire, Ch. (1995). El pintor de la vida moderna. Murcia: Colegio Oficial de Aparejadores y Arquitectos Técnicos de Murcia. 4.

Benjamín, W. (2005). El libro de los pasajes. Madrid: Celeste Ediciones.

Bourdieu, P. (2012). Bourdieu en Argelia. Imágenes del desarraigo. Catálogo de la exposición Pierre.

Bourdieu, P. y Waqcuant, L. (2005). Una invitación a la sociología reflexiva. Siglo XXI editores Argentina.

Calvo, C. (1987). «Educación v/s Escolarización». El Canelo. Revista Chilena de Desarrollo Local. 2(2)18-20, marzo.

Calvino, I. (1972). Las ciudades invisibles. Madrid: Siruela.

Corporación Mandala. (2015). Seminario «Proceso de paz, gobernanza local y perspectiva de paz urbana». Instituto de Estudios Regionales de la Universidad de Antioquia y Confiar.

Defensoría del pueblo. Defensoría delegada para la prevención de riesgos de violaciones de DDHH y DIH. Sistema de Alertas Tempranas-SAT. (6 de Marzo de 2013). Informe de Riesgo N 008-13. Medellín.

Debord, G. (1999). La sociedad del espectáculo. Valencia: Pre-textos

- (2000). Los «no lugares» espacios del anonimato: Una antropología de la sobremodernidad ( $5^{\mathrm{a}}$ ed). Barcelona: Gedisa.

Diario el País \& Fundación Buen Gobierno (Marzo de 2015). «Foro por la paz en Colombia». Foro llevado a cabo en Madrid, España

Durán Segura, L. (2011). «Miradas urbanas sobre el espacio público: el flâneur, la deriva y la etnografía de lo urbano». Reflexiones, 90(2): 137-144, ISSN: 1021-1209/2011.

Echavarría, J. M. (2009). «La guerra que no hemos visto». En: http://www. laguerraquenohemosvisto.com/english/principal.html

Estrela Cerveró, M. y Martínez Bonafé, J. (2012). «Pasos que (nos) construyen: Nuevas formas de documentar la ciudad a través de la deriva». Revista Educación física y deporte, 31(1), pp. 905-911.

- y Martínez Bonafé, J. (2014). «Aprendre a la ciutat a través de la deriva». Kultur: Revista interdisciplinaria sobre la cultura de la ciutat, 1(1), pp. 215-222. 
Infante Márquez, A. (2013). «El papel de la educación en situaciones de posconflicto: estrategias y recomendaciones». HALLAZGOS. ISSN: 1794-3841. Año 11, N. 21. Bogotá, DC. Universidad Santo Tomás, pp. 223-245, pág. 229.

Instituto Catalán internacional para la Paz. (2014). Escenarios posconflicto en Colombia. Agenda, oportunidades y hoja de ruta. Barcelona.

Larrosa, J. (2003). «Conferencia para Doctorado en Educación». Universidad de Valencia. Auditorio central. Valencia, España.

López Rodríguez, S. (2005). Orientación y desorientación en la ciudad. La teoría de la deriva. Indagación en las metodologías de evaluación de la ciudad desde un enfoque estético-artístico. Granada: Editorial de la Universidad de Granada.

Martínez Bonafé, J. (2010). «La ciudad en el currículum y el currículum en la ciudad». En J. Gimeno (ed.), Saberes e incertidumbres sobre el currículum (págs. 527-547). Madrid: Morata.

Moreno, W. (2005). «Milicia y escuela: proxémica icónica de los juegos de guerra. (Apuntes prosaicos para una genealogía de la educación física en Antioquia)», Revista Educación y Pedagogía, Medellín, Universidad de Antioquia, Facultad de Educación, vol. XVII, núm. 42 (18), (mayo-agosto), pp. 101-119.

- (2009). «Escuela, cuerpo y milicia, historias de un redoble, de un simulacro que no termina». Educare em revista, 33, pp. 93-110.

— y Pulido, S., Gaviria, N., Herrera, M. I., \& Hincapié, D. (2015). Las prácticas de deporte, recreación y actividad física en la construcción de la trama social en la ciudad de Medellín 2013-2014. Medellín: INDER.

— y Gómez, M. F., Vásquez, A., Gaviria, N., Londoño, D., Santa, S., HinCapié, D., Marulanda, S., Correa, C. (2015). El deporte y la convivencia en los procesos de transformación social de Medellín (2012-2014). Medellín: INDER (En imprenta).

Morín, E. (1994). Introducción al Pensamiento complejo. Barcelona: Gedisa.

Pearce, J. (2014). «Estrategias para enfrentar los ciclos de la violencia intergeneracional en Colombia: hacia una "violentología» que sirva a la paz». En documentos del seminario «Escenarios posconflicto en Colombia agenda, oportunidades y hoja de ruta» Barcelona. Instituto Catalàn Internacional para la paz. Disponible en: http://icip.gencat.cat/web/.content/continguts/publicacions/documents_i_informes/2014/Relatoria_escenarios_posconflicto_Colombia_2014.pdf 
Personería de Medellín (2014). Informe sobre la situación de los derechos humanos en la ciudad de Medellín 2014. Medellín: Universidad de Medellín.

Popkewitz, Thomas S. (1994). Sociología politica de las reformas educativas: el poder/saber en la enseñanza, la formación del profesorado y la investigación. Madrid: Ediciones Morata

Schultheis, F. y Frisingheldi, Ch. (ed.) (2011). Bourdieu en Argelia. Imágenes del desarraigo. Madrid: Círculo de Bellas Artes, p. 243.

Shirley, D. \& Hargreaves, A. (2012). La cuarta Vía. El prometedor futuro del cambio educativo. Barcelona: Octaedro.

— y Beatriz, M., Fernández, M., Ossa, A. y Borba, G. (2013). «La Cuarta Vía de liderazgo y cambio en América Latina: perspectivas en Chile, Colombia y Brasil». Pensamiento Educativo: Revista de Investigación Educacional Latinoamericana, 2013, 50(2), pp. 5-27.

SuARez, H. (2008). Cuaderno de ciencias sociales. La fotografía como fuente de sentidos. FLACSO.

UNICEF (28 de marzo de 2016). Niños nacidos en conflicto: 87 millones de niños solo conocen la guerra: UNICEF. Obtenido de UNICEF: https:// www.unicef.es/actualidad-documentacion/noticias/ninos-nacidos-en-conflicto

Velarde, S. (2008). «Sociología de la vida cotidiana». Ponencia presentada en el Ciclo Temáticas, Problemáticas en Sociología Universidad Autónoma de Ciudad Juárez, 4 abril 2006-04-08. http://sincronia.cucsh. udg.mx/velardew06.htm.

Verdad ABIERTa. «Cuatro comunas de Medellín en riesgo: defensoría». (22 de marzo de 2016). Obtenido de Verdadabierta.com: http://www.verdadabierta.com/la-historia/54-noticias/generales/4509-medellin-en-riesgo-defensoria-del-pueblo

Wacquant, L. (2006) Entre las cuerdas: cuadernos de un aprendiz de boxeador. Buenos Aires: Siglo XxI. Editores Argentina. 
